\title{
Fatigue crack growth in a metastable austenitic stainless steel
}

\author{
D.F. Martelo and M.D. Chapetti ${ }^{*}$ \\ Laboratory of Experimental Mechanics (LABMEX) Research Institute for Material Science (INTEMA) \\ CONICET - Faculty of Engineering, National University of Mar del Plata \\ J.B. Justo 4302, 7600 Mar del Plata, Argentina \\ * Corresponding author: mchapetti@fi.mdp.edu.ar
}

\begin{abstract}
Fatigue crack growth in a metastable austenitic stainless steel was investigated in thin specimen under positive stress ratio. Annealed conditions were used to test the influence of the microstructure. The influence of load ratio on propagation threshold and propagation behavior was analyzed using the Elber's closure approach, the Donald and Paris partial crack closure and the empirical Kujawski $(\Delta \mathrm{K} \cdot \mathrm{Kmax})^{\alpha}$ parameter. Results show that load ratio effects are not completely explained by these approaches. It was found that the threshold of the material in the annealed condition depends on the load history, especially when the load ratio is low. It seems that the amount of martensite transformation is responsible for the observed differences in fatigue crack growth resistance.
\end{abstract}

Keywords: Fatigue, crack propagation, thresholdMetastable austenitic stainless steel

\section{Introduction}

In the last years, the competitiveness in the automotive sector and the compliance with higher environmental standards has forced the development of new light-weight materials. One of the materials that fulfill with the exigencies of automotive sector are the metastable stainless steels because of they combine good corrosion resistance with versatile mechanical properties [1,2]. Due to his high ultimate strength, metastable stainless steel allows the use of components of less thickness. One of the more important aspects in the automotive sector is the design again fatigue damage.Traditionally, the approach to fatigue design based on the cyclic stress range $\Delta$ Shas been used [3]. However, thin walled light components must be designed using more conservative approach, basedmainly in linear elastic fracture mechanics.

AISI 301LN steels belong to the metastable austenitic steels and have an austenitic structure in annealed conditions which confers them an excellent ductility. Besides, they have an extraordinary strain hardening because of the transformation of austenite to martensite during deformation. This particular class of steels are called TRIP steels [4]. Significant researches have been conducted on the fatigue behavior of TRIP steels [4-12], and depending of the testing condition, different behaviors have been reported. In the high cycle (HCF) regime, i.e. test under load control or test under $\mathrm{K}$ control, the conclusion of the studies show that exists a relationship between the martensitic transformation around the crack tip and the decrease in the fatigue crack growth rate (FCGR) [4-8,10,12], with the exception of reference [9], where it attributed the decrease in the FCGR to the slip characteristic rather than the martensitic transformation. Until now various mechanisms have been proposed trying to explain how the martensitic transformation can affect the FCGR. However, there is no mechanism that can explain satisfactorily the effect of the martensitic transformation over the FCGR having accounted the entire picture of the stress state.

The most recurrent mechanism to explain the crack growth retardations in fatigue is the crack closure, which was introduced by Elber in 1971 [13], after observing that fatigue crack surfaces contact under cyclic tensile loading. Even direct measurements have not been achieved, is felt that the martensitic transformation cause crack closure because of the involved volume expansion of 1-4 \% [14]. The first mechanism used to explain the premature contact between the faces of the crack is the plasticity induced crack closure. However, others mechanisms induced crack closure 
have been identified, as oxide induced crack closure or roughness induce crack closure. The vast majority of mechanisms to explain crack closure are explained, for instance, in the book "Fatigue of Material" written by S.Suresh [3]. Traditionally, in some expression obtained from experimental investigations have been indicated that the crack opening stress intensity factor $K_{\mathrm{op}}$ is only function of the stress ratio $R[13,15]$. However, some authors recognized that $K_{\mathrm{op}}$ is also influenced by the specimen geometry, the stress state, the stress intensity factor range and the environment. Some models have been theoretically developed in order to explain how the crack opening stress is influenced by the stress ratio $R$, the maximum applied stress or load level $\mathrm{P}_{\max }$, and the crack front constraint (plane stress or plane strain behavior).

In this work the fatigue crack growth behavior of an annealed metastable austenitic stainless steel was investigated in thin specimen under positive stress ratio. The influence of load ratio on propagation threshold and propagation behavior was analyzed using the Elber's closure approach, the Donald and Paris partial crack closure approach and the empirical Kujawski $(\Delta \mathrm{K} \cdot \mathrm{Kmax})^{\alpha}$ parameter. Results are analyzed in order to look for answers about the influence of the martensitic transformation on the fatigue behavior of this kind of steel and for a unique relationship between fatigue crack propagation rate and the applied driving force.

\section{Experiments}

The material utilized in the current study was an annealed austenitic stainless steel AISI 301LN provided by OCAS NV, Arcelor-Mittal R\&D Industry Gent (Belgium) The chemical composition of this material is shown in Table 1. The microstructure of the material is shown in figure 1 . The

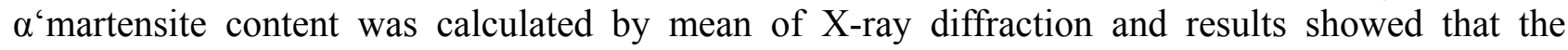
martensite content was less than $2 \%$.

Table 1.Chemical Composition

\begin{tabular}{|l|l|l|l|l|l|l|l|l|l|l|}
\hline AISI 301LN & FE & $\mathrm{Cr}$ & $\mathrm{Ni}$ & $\mathrm{Mo}$ & $\mathrm{C}$ & $\mathrm{Si}$ & $\mathrm{P}$ & $\mathrm{S}$ & $\mathrm{Mn}$ & $\mathrm{Cu}$ \\
\hline Annealed & bal & 17.94 & 6.30 & 0.18 & 0.016 & 0.513 & 0.032 & 0.005 & 1.481 & 0.135 \\
\hline
\end{tabular}

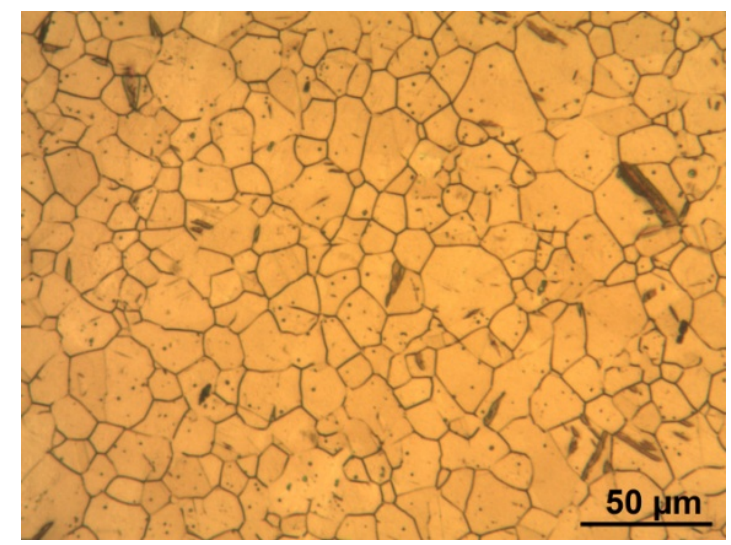

Figure 1.Microstructure of annealed AISI 301LN stainless steel

Table 2.Mechanical and thermo-mechanical properties

\begin{tabular}{|c|c|c|c|c|c|}
\hline$\sigma_{\mathrm{ys}}$ & $\sigma_{\mathrm{UTS}}$ & Elongation $(\mathrm{Pct})$ & $\mathrm{Ms}\left({ }^{\circ} \mathrm{C}\right)$ & $\mathrm{M}_{\mathrm{d} 30}\left({ }^{\circ} \mathrm{C}\right)$ & $\mathrm{M}_{\mathrm{d}}\left({ }^{\circ} \mathrm{C}\right)$ \\
\hline $343 \mathrm{MPa}$ & $973 \mathrm{MPa}$ & 39,39 & -66.015 & 49.042 & $100^{*}$ \\
\hline
\end{tabular}

*For AISI 301 stainless steel.

Single edge notch test specimen (SENT) of $1 \mathrm{~mm}$ thickness and a width of $35 \mathrm{~mm}$ and $40 \mathrm{~mm}$, were 
machined with the rolling direction parallel (T-L) and perpendicular (L-T) to the notch. The specimens were fatigued in air and at room temperature.

The FCGR test were conducted in an Instron's servo-hydraulic machine with closed loop to computers for automatic test control and data acquisition. The crack extension was measured with a krak-gages ${ }^{\circledR}$ technique, which is principally an indirect DC potential measurement procedure. The krag-gages ${ }^{\circledR}$ theory is explained in reference [16]. For instance, the crack gauge KG-B20, whose full scale is $20 \mathrm{~mm}$, has a sensitivity of measurement to crack extension that is better than $0.02 \mathrm{~mm}$ [17]. The crack extension was also measured using the compliance technique by means of a clip gage in the crack mouth and a strain gauge fixed in the back surface.

The crack closure measurementwere made by using a sampling rate of 400 data pairs (load and displacement) per cycle according to some of the recommendations made by Song et al. [18]. The signal noise was reduced by using low-pass digital filters [19]. The determination of the opening force was done by comparing slope segments of 10 percent of the load- displacement data with the linear region of the load-displacement curve.

The fatigue tests were performed at a frequency of $20 \mathrm{~Hz}$. Three different values of load ratio $\mathrm{R}$ $\left(=\sigma_{\min } / \sigma_{\max }\right) 0.1,0.3,0.5,2$ different stress level at the same load ratio, and 3 decreasing $\Delta \mathrm{K}$ at different load ratio were employed. For $\Delta \mathrm{K}$ decreasing test the rate of force shedding with increasing crack size was according to the ASTM standard (20). The details of the experiments are listed in table 3.

The martensite transformation around the crack tip was observed by optical microscopy. The material was ground in the surface where the fatigue crack was going to appear with SiC emery paper up to a roughness of 1200 grit and then polished. Because of the mechanical grinding can induce martensitic transformation, the material was electro-polished with a solution consisting of $5 \mathrm{vol} \%$ perchloric acid and $95 \%$ ethanol at $45 \mathrm{~V}$ for $15 \mathrm{~s}$. The martensitic phase was revealed by chemical etching in a solution of $100 \mathrm{ml}$ ethanol, $20 \mathrm{ml} \mathrm{HCl}, 1.5 \mathrm{~g} \mathrm{~K}_{2} \mathrm{~S}_{2} \mathrm{O}_{5}$ and $2 \mathrm{~g} \mathrm{NH} 4 \mathrm{~F} \cdot \mathrm{HF}$. The electro-polished was used until no peak (100) (200) (211) ( $\alpha$ 'martensite peak according to M. Karimi et al [21]) was found by X-ray diffraction.

Table 3.Details of test configuration

\begin{tabular}{|c|c|c|c|c|c|c|c|}
\hline & Specimen & $\begin{array}{c}\mathrm{R} \\
\left(\sigma_{\min } / \sigma_{\max }\right)\end{array}$ & $\begin{array}{l}\text { Load level }[\mathrm{N}] \\
\left(\mathrm{P}_{\max }-\mathrm{P}_{\min }\right)\end{array}$ & $\begin{array}{l}\text { Notch } \\
{[\mathrm{mm}]}\end{array}$ & Test Type & $\begin{array}{c}\mathrm{W} \\
{[\mathrm{mm}]}\end{array}$ & $\begin{array}{c}\mathrm{C} \\
{\left[\mathrm{mm}^{-1}\right]}\end{array}$ \\
\hline 1 & NL2 & 0.5 & 2625 & 8.729 & $\begin{array}{c}\text { Constant amp. } \\
\text { load }\end{array}$ & 35 & - \\
\hline 2 & NL3 & 0.1 & 2625 & 8.600 & $\begin{array}{c}\text { Constant amp. } \\
\text { load }\end{array}$ & 35 & - \\
\hline 3 & NL4 & 0.1 & 1815 & 13.817 & $\begin{array}{c}\text { Constant amp. } \\
\text { load }\end{array}$ & 35 & \\
\hline 4 & NL6 & 0.3 & 1890 & 14.020 & $\begin{array}{c}\text { Constant amp. } \\
\text { load }\end{array}$ & 35 & - \\
\hline 5 & NL7 & 0.7 & 2625 & 8.927 & $\begin{array}{c}\text { Constant amp. } \\
\text { load }\end{array}$ & 35 & - \\
\hline 6 & NL9 & 0.1 & variable & 9.777 & $\Delta \mathrm{K}$ decreasing & 40 & -0.08 \\
\hline 7 & L3G & 0.5 & variable & 11.55 & $\Delta \mathrm{K}$ decreasing & 40 & -0.065 \\
\hline 8 & NNL4 & 0.7 & variable & 9.088 & $\Delta \mathrm{K}$ decreasing & 35 & -0.055 \\
\hline 9 & NNL7 & 0.7 & variable & 8.897 & $\Delta \mathrm{K}$ decreasing & 35 & -0.09 \\
\hline 10 & NNL1 & 0.5 & variable & 8.912 & $\Delta \mathrm{K}$ decreasing & 35 & -0.08 \\
\hline
\end{tabular}




\section{3. $\Delta \mathrm{K}$ expressions}

In situations where the linear elastic fracture mechanics theory (LEFM) is valid the crack driving force is traditionally represented by using the stress intensity factor $\Delta \mathrm{K}$. For the specimen type used in this investigation and for the grid constraint of our test's machine, the stress intensity factor for the specimen of this investigation is not tabulated in books, therefore the finite element method (FEM) was employed to obtain the value of the stress intensity factor. Figure 2 shows the $\Delta K$ solutions used for the two configurations that have been used for test. The typical solution available in literature for SENT specimens is also shown and the difference in the given $K$ values for a given crack length can be clearly observed. The curve was normalized by dividing the stress intensity factor by the applied stress and the crack length by the specimen length.

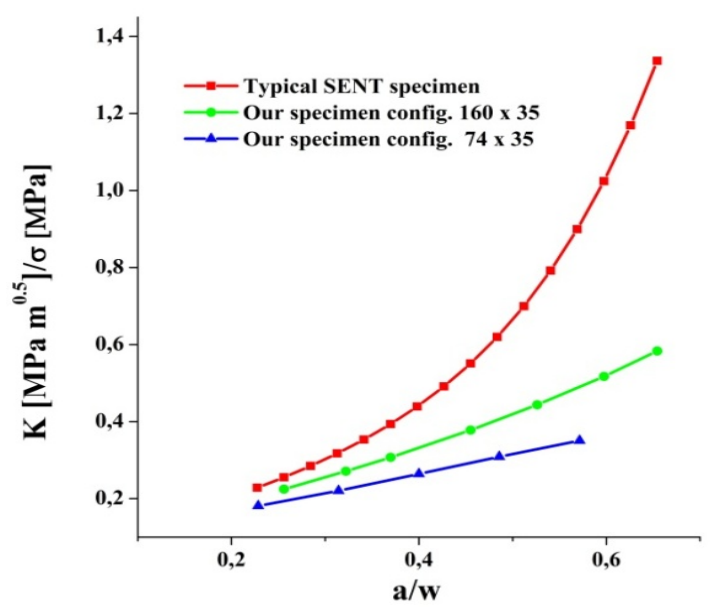

Figure 2. Stress intensity factor obtained by finite element models for the used configurations.

\section{Experimental Results}

\subsection{Results using the range of the stress intensity factor}

The fatigue crack growth rates of austenitic stainless steel 301LN at room temperature, at 3 different load ratios and different load levels are shown in Fig. 3(a). For all test conditions the crack growth rate increases with increase in $\Delta K$. The curves show a trend that can be considered linear with positive and constant slope. The influence of load level is negligible, in spite of we found some papers that mention that some austenitic stainless materials in specimen with thin section $[7,22]$ suffer the influence of stress level on fatigue crack growth rate.
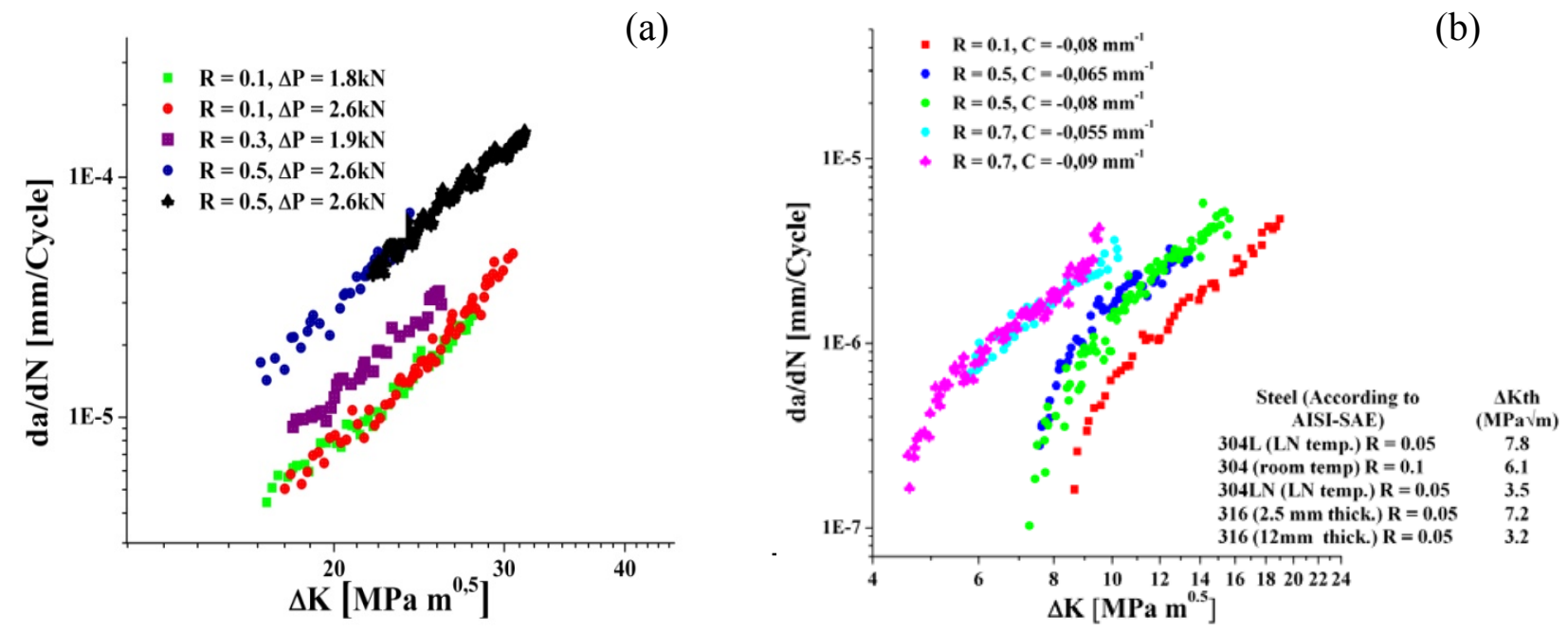
Figure 3. Fatigue crack growth rate vs stress intensity factor range at different load ratios (a) in the stable crack propagation region and (b) in the near threshold region.

The influence of $\mathrm{R}$ values on near threshold crack growth rates is shown in Fig. 3(b). It can be seen how the $\Delta \mathrm{K}_{\text {th }}$ decreases with the increment in load ratio. The values of $\Delta \mathrm{K}_{\text {th }}$ are relatively high, especially at $\mathrm{R}=0.1$ and $\mathrm{R}=0.5$, in comparison with other austenitic stainless steel alloys or even other steel alloys. However the results are not surprising, according to the results found for other austenitic stainless steel that are shown in the table of Fig.3(b), where it can be observed that materials with martensitic transformation and/or in conditions of plane stress, produce high thresholds.

\subsection{Results using the effective stress intensity factor}

The fatigue crack growth rate was plotted also by using the conventional Elber's approach and defining the effective stress intensity range as:

$$
\Delta K_{e f f}=K_{\max }-K_{o p}
$$

Fig. 4 shows the obtained results. They show that in the stable region (far from thresholds) the crack closure is practically constant in the total range of crack propagation for the same test. It is only observes the same average value of $\mathrm{S}_{\mathrm{o}} / \mathrm{S}_{\max } \approx 0.35$ for both cases at low load ratio $(\mathrm{R}=0.1$ and 0.3$)$. The analysis was based in the work of J. Song et al [18], from which the offset criterion that better estimate load ratio effects in the Paris region is $4 \%$ (this analysis will be detailed in a paper that will be soon submitted for publication).

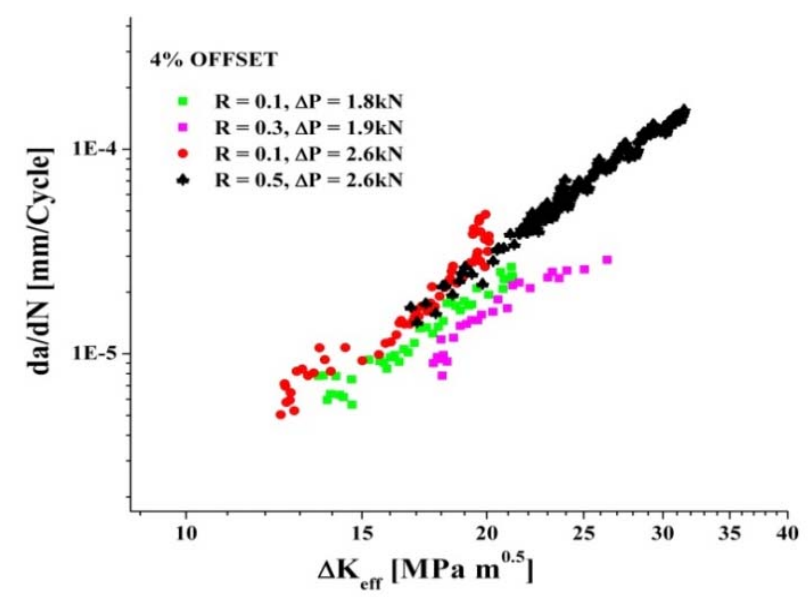

Figure 4. Fatigue crack growth rate as a function of the effective stress intensity factor

Fig. 5 shows the correlation obtained using Eq. (1) for the near threshold behavior. It shows that with the use of crack closure concepts the curves move closer each other but it is still not possible to join them in a unique curve. In this region of slow growth rate the relation of $K_{\mathrm{op}} / K_{\max }$ increase with decreasing the range of the stress intensity factor (approaching the threshold).

\subsection{Results using the Donald`s effect}

The original concept of crack closure indicates that the crack cannot grow if the crack is not fully open. However Donald and coauthors have shown that the interference of crack faces does not 
shield completely the crack tip from fatigue damage [23]. Based on this concept, Donald proposed to calculate an effective stress intensity factor range as:

$$
\Delta K_{2 / P I}=\Delta K_{a p p}-\frac{2}{\pi}\left(K_{o p}-K_{\text {min }}\right)
$$

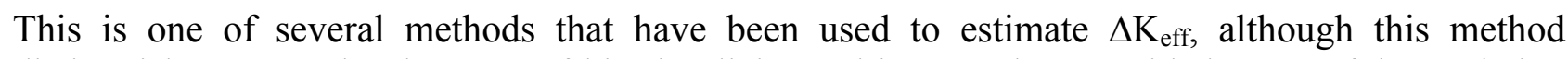
distinguishes over other because of his simplicity and because has provided successful correlation of the crack growth rate data for aluminum alloys. Fig. 6 shows the fatigue crack growth rate as a function of the effective stress intensity factor proposed by Donald. It can be observed that for our analyzed material the Donald's effect does not provide a better correlation of the R-ratio effects than the traditional $\Delta \mathrm{K}_{\text {eff }}$ calculated by using the Eq. (1).

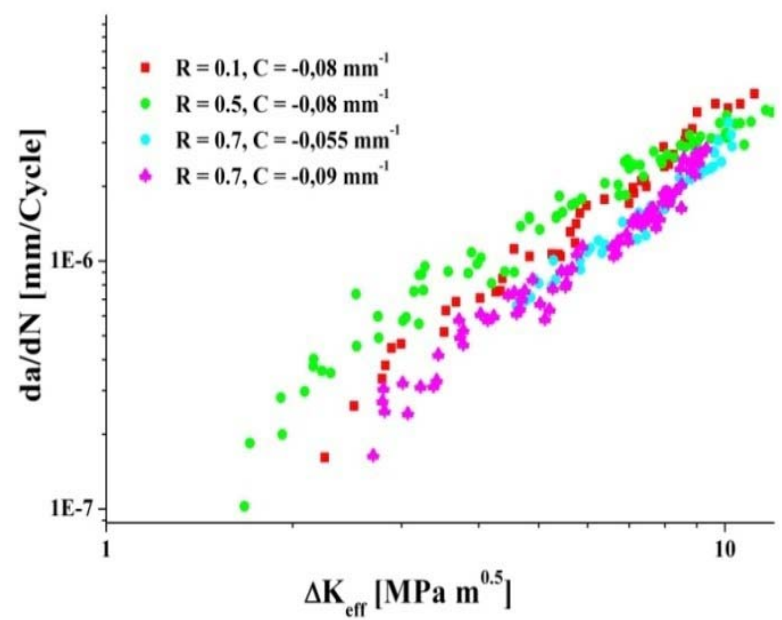

Figure 5. Fatigue crack growth rate as a function of the effective stress intensity factor
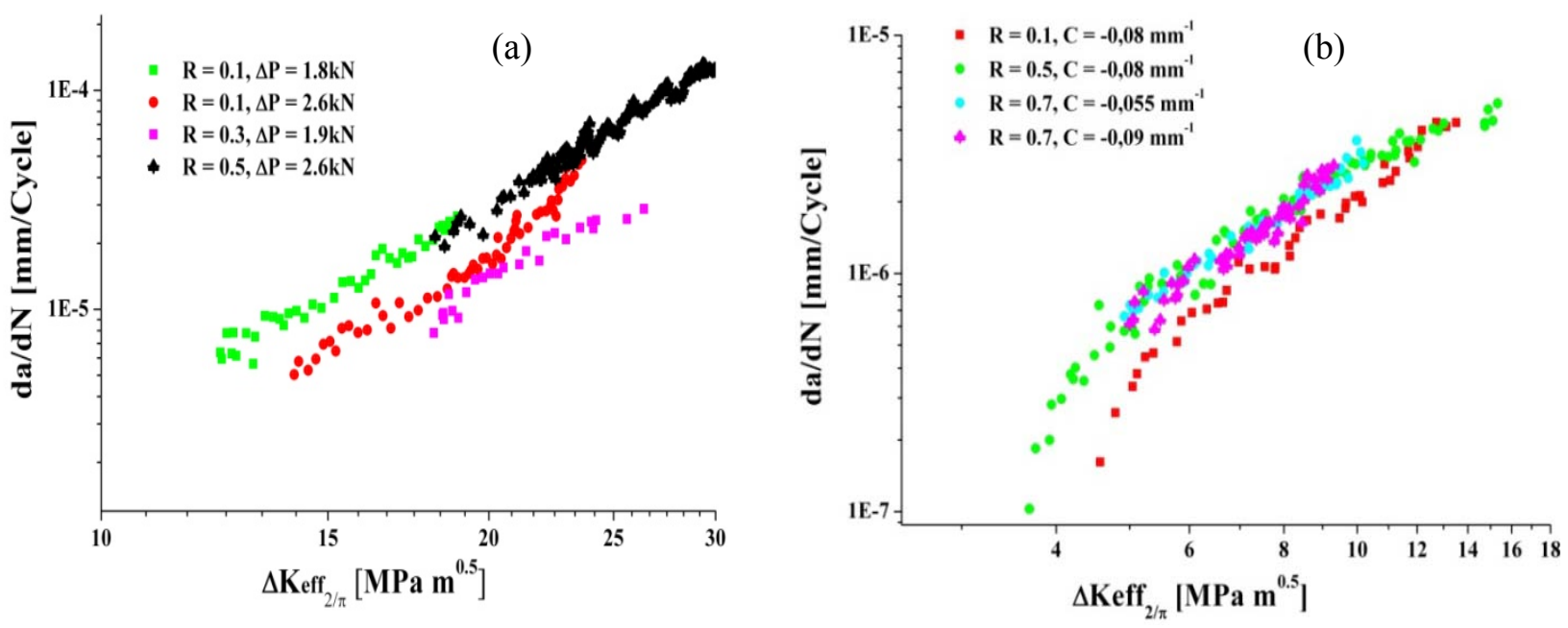

Figure 6. Fatigue crack growth rate as a function of the effective stress intensity factor proposed by Donald et al. (a) in the stable crack propagation region and (b) in the near threshold region.

\subsection{Results using the Kujawski`s Parameter}

To explain the load ratio effects in fatigue crack growth, and because of the inconsistency in the measurement of crack closure and the difficulties to determine the fatigue damage associated to a crack partially open, Kujawski proposed a crack driving force parameter that is calculated by using 
$\mathrm{K}_{\max }$ and $\Delta \mathrm{K}[24]$ as follow:

$$
K^{*}=\left(K_{\max }\right)^{\alpha}(\Delta K)^{1-\alpha}
$$

Where $\Delta \mathrm{K}$ is the positive part of the range of the applied stress intensity factor. This parameter is characterized, among other things, by the use of two separate variables that could describe unambiguously the load cycle at least if the load ratio is positive and $\mathrm{K}_{\max }$ is greater than 0 , like in the present case. The $\alpha$ value is a factor that determines the importance of $K_{\max }$ or $\Delta K$ and it is calculated by means of the following expression:

$$
\alpha=\frac{\log \left(\Delta K_{1} / \Delta K_{2}\right)}{\log \left(\left(1-R_{1}\right) /\left(1-R_{2}\right)\right)}
$$

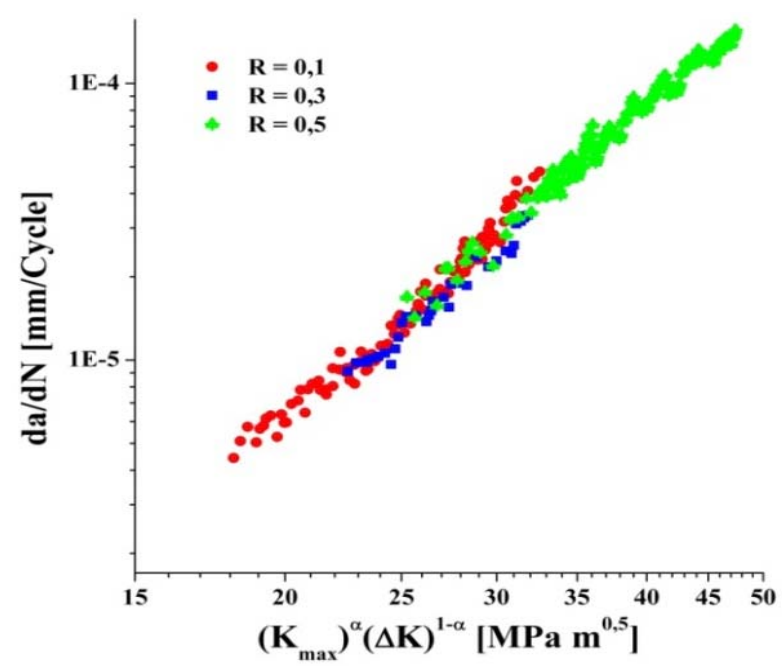

Figure 7. Fatigue crack growth rate as a function of the Kujawski`s parameter with $\alpha$ equal to 0.6.

Using Eq. (4) the average $\alpha$ value, for the AISI $301 \mathrm{LN}$ in the paris region, was equal to 0.6. This was the same $\alpha$ value found for the metastable austenitic stainless steel AISI 304L tested at 77K [8], although in that case the scatter was higher. Fig. 7 shows the correlation obtained by plotting the fatigue crack growth rate vs the Kujawski's parameter far from the threshold region. It is seen that kujawski's parameter can unify the curves of the test performed to constant load ratio into a master curve that can be described by using Eq (5) with $\mathrm{C}=1.33 \times 10^{-11}\left[\mathrm{~mm} /\right.$ cycle $\left.\mathrm{MPa} \mathrm{m} \mathrm{m}^{0.5 \mathrm{~m}}\right]$ and $\mathrm{m}=$ 3.619 .

$$
\frac{d a}{d N}=C\left(\Delta K^{1-\alpha} K_{m a x}^{\alpha}\right)^{m}
$$
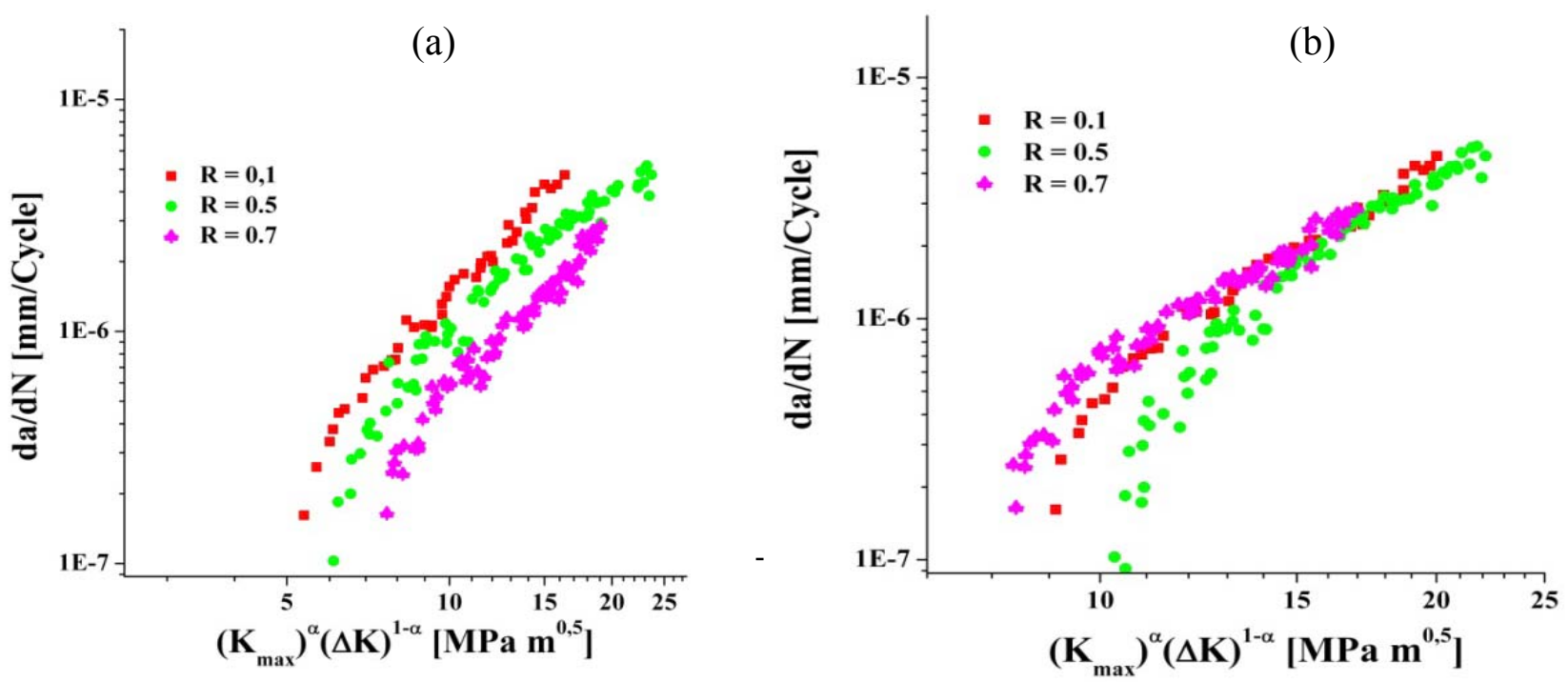
Figure 8.Fatigue crack growth rate as a function of the Kujawski`s parameter with (a) $\alpha$ equal to 0.6 and (b) $\alpha$ equal to 0.5

The same parameter $\alpha$ that was found to correlate the fatigue crack growth rate curves in Fig. 7 has been used to analyze the near threshold region, and results are shown in Fig 8(a). It can be observed that in this case the approach cannot success as in Fig. 7. Fig.8(b) shows results obtained by using an $\alpha$ value equal to 0.5 . Even though results seem to be somehow better, the approach does not success.

It is interesting to note that the value of $\alpha$ parameter calculated for the AISI 301LN decrease with the decrease of the stress intensity factor range and/or with the decrease of the martensite content. This result agree with those of the work of S.Kalnaus et al [11], were they estimated an $\alpha$ parameter equals to 0.36 for an austenitic steel without transformation. According to our measurements, the martensite content decreases in the near threshold region of crack propagation with respect to measurement made in the relative high $\Delta \mathrm{K}$ fatigue crack propagation region. It is clear that further and more detailed analyses are needed in order to explain the influence of the load ratio $\mathrm{R}$ in this region.

\section{Concluding remarks}

Fatigue crack growth of aannealed metastable austenitic stainless steel was investigated in thin specimen under positive stress ratio. The influence of load ratio on propagation threshold and propagation behavior was analyzed using the Elber`s closure approach, the Donald and Paris partial crack closure and the empirical Kujawski $(\Delta \mathrm{K} \cdot \mathrm{Kmax})^{\alpha}$ parameter.

Results show that load ratio effects are not completely explained by these approaches. The crack closure effect approaches (both, the traditional Elber approach and its modification by Donald and Paris) cannot explain the influence of the stress ratio $\mathrm{R}$ on the fatigue crack propagation rate on the analyzed thin specimens of a TRIP material.

The two parameter crack driving force $(\Delta \mathrm{K} \cdot \mathrm{Kmax})^{\alpha}$, with $\alpha=0.6$, seem to be a proper parameter to uniquely explain the fatigue behavior of the analyzed TRIP steel for positive R ratios far from the threshold region. However, it seems to fail in the threshold region, where the crack closure levels are important, and a unique $\alpha$ value cannot be found. So, further investigation should be carried out in order to explain these results.

\section{Acknowledgements}

Authors wish to express their gratitude to the funding provided by CONICET (National Research Council), and by Agencia Nacional de Promoción Científica y Tecnológica (ANPCyT), Argentina (PICT2010 Nro.0379).

\section{References}

[1] S. Lamb, Handbook of Stainless Steels and Nickels Alloy, CASTI Publishing Inc, Edmonton, 2001. 
[2] H. Hallberg, L. Banks-Sills, M. Ristinmaa, Crack tip transformation zones in austenitic stainless steel. ENG FRACT MECH, 79 (2012) 266-280.

[3] S. Suresh, Fatigue of Materials, Cambridge University Press, Cambridge, 1998.

[4] G.R. Chanani, S.D. Antolovich, W.W. Gerberich, fatigue Crack Propagation in Trip Steels. METALL MATER TRANS B, 3 (1972) 2661 - 2672.

[5] A.G. Pineau, R.M. Pelloux, Influence of Strain-induced Martensitic Transformation on fatigue Crack Growth rates in Stainless Steels. METALL MATER TRANS B, 5 (1974) 1103-1112.

[6] E. Hornbogen, Martensitic Transformation at a Propagating Crack. ACTA METALL MATER, 26 (1978) 147-152.

[7] G. Schuster, C. Altstetter, Fatigue of Annealed and Cold Worked Stable and Unstable Stainless Steels. METALL TRANS A, 14 (1983) 2077-2084.

[8] Z. Mei, J.W. Morris, Influence of deformation-induced martensite on fatigue crack propagation in 304-type steels. METALL TRANS A, 21 (1990) 3137-3152.

[9] W.Y. Maeng, M.H. Kim, Comparative study on the fatigue crack growth behavior of 316L y 316LN stainless steel: Effect of microstructure of cyclic plastic strain zone at crack tip. J NUCL MATER, 282 (2000) 32-39.

[10] S. Biswas, S. Sivaprasad, N. Narasaiah, S. Tarafder, P.C. Chakraborti, Load history effect on FCGR behaviour of 304LN stainless steel. INT J FATIGUE, 29 (2007) 786-791.

[11] S. Kalnaus, Y. Jiang, A.K. Vasudevan, An experimental investigation of Fatigue crack Growth of stainless steel 304L. INT J FATIGUE, 31 (2009) 840-849.

[12] X. Cheng, R. Petrov, L. Zhao, M. Janssen, Fatigue Crack growth in TRIP steel under positive R - ratios. ENG FRACT MECH, 75 (2008) 739-749.

[13] W. Elber, The significance of fatigue crack closure, in: M.S. Rosenfeld (eds.), Damage tolerance in aircraft structures ASTM STP 486, Philadelphia, 1971, pp. 230-242.

[14] P. Hedstrom, Deformation induced martensitic transformation of metastable stainless steel AISI 301, Lulea, Lulea University of Technology, 2005.

[15] J. Schijve, Some formulas for the crack opening stress level. ENG FRACT MECH, 14 (1981) 461-465.

[16] H.R. Hartmann, R.W. Churchill. KRAK-GAGE: A new Transducer for Crack Growth Measurement. Presented at the Society for Experimental Stress Analysis Fall Meeting, sponsored by the Society for experimental Stress Analysis, 1981.

[17] TTI Division, Hartrun Corporation. Krak-gage Accuracy and Resolution. Chaska Minnesota : s.n., 1981. KRAK-TIP No. 8109-1.

[18] J.H. Song, Y.I. Chung, Improvement of ASTM compliance offset method for precise determination of crack opening load. INT J FATIGUE, 31 (2009) 809-819.

[19] C.Y. Kim, J.H. Song, An automated procedure for determining crack opening level from differential displacement signal data, INT J FATIGUE, 15 (1993) 477-489.

[20] E647-08E01, standard Test Method for Measurement of fatigue Crcak Growth Rates. Annual Book of ASTM Standards ASTM. Philadelphia : s.n., 2010.

[21] M. Karimi, A. Najafizadeh, A. Kermanpur, M. Eskandari. Effect of martensite to austenite reversion on the formation of nano/submicron grained AISI 301 stainless Steel. MATER CHARACT, 60 (2009) 1220-1223.

[22] D.G. Rickerby, P. Fenici, Fatigue Crack Growth in thin section Type 316 Stainless Steel. ENG FRACT MECH, 19 (1984) 585-599.

[23] P. Paris, H. Tada, J.K. Donald, Service load fatigue damage - a historical perspective. INT J FATIGUE,21 (1999) S35-S46. 
[24] D. Kujawski, A fatigue crack driving force parameter with load ratio effects. INT J FATIGUE, 23 (2001) S239-S246. 